\title{
COMO DESESTRUTURAR UMA AgÊNCIA REGULADORA EM PASSOS SIMPLES
}

\author{
EDUARDO JORDÃO ${ }^{\dagger}$ \\ MAURÍCIO PORTUGAL RIBEIRO ${ }^{\dagger \dagger}$
}

\section{UM DOSSIÊ SOBRE ESTADO ADMINISTRATIVO}

\begin{abstract}
Palavras-Chave: Agência Reguladora; Corpo Diretor; Estado Administrativo; Direito Administrativo.
\end{abstract}

KEYWORDS: Administrative Agency; Administrative Agency's Board; Administrative State; Administrative Law.

\footnotetext{
† Professor da FGV Direito Rio. Doutor em Direito Público pelas Universidades de Paris (Panthéon-Sorbonne) e de Roma (Sapienza), em cotutela. Master of Laws (LL.M) pela London School of Economics and Political Science (LSE). Mestre em Direito Econômico pela Universidade de São Paulo (USP). Bacharel em Direito pela Universidade Federal da Bahia (UFBA). Foi pesquisador visitante na Yale Law School, nos Estados Unidos, e pesquisador bolsista nos Institutos Max-Planck de Heidelberg e de Hamburgo, na Alemanha.

† Sócio do Portugal Ribeiro Advogados, Professor da Pós-Graduação da Faculdade de Direito da FGV, São Paulo, Ex-Professor da disciplina Direito de Infraestrutura do Curso de Graduação em Direito da FGV, Rio de Janeiro (2009-2012), Ex-Chefe do Departamento de Consultoria em Infraestrutura para o Brasil, no IFC - Internationa Finance Corporation, instituição do Grupo Banco Mundial (2008-2011), Ex-Chefe ("Director") para os Setores de Infraestrutura e Setor Público, no Citibank Brasil (20072008), Ex-Conselheiro de Administração da CHESF (2005-2007), CEG (2005-2007) e ACESITA (2006-2007), Mestre em Direito (LL.M.), pela Harvard Law School (2004). Foi um dos redatores do projeto de lei de PPP, que virou a Lei no ${ }^{\circ} 11.079 / 04$. Foi um dos redatores da parte da Lei no 11.096/06, que reformou a Lei no 8.987/95 (a Lei Geral de Concessões). Como advogado de entes da iniciativa privada, participou das discussões que geraram as Medidas Provisórias nº 575/12 e nº 752/16.
} 
SUMÁRIO:

I. INTRODUÇÃO................................................................................................182

II. AS DICAS PARA OS CHEFES DOS PODERES EXECUTIVOS .................183

1. Enfraqueça o corpo diretor das agências reguladoras ......183

2. Prejudique a operação da agência.........................................186

3. Exponha as decisões das agências a todo tipo de controle.190

III. AS DICAS PARA OS ÓRGÃOS DE CONTROLE...........................................193

1. Limite o leque de ações ou instrumentos à disposição das agências.

2. Usem os poderes de punição para amedrontar os funcionários das agências ....................195

3. Interfira nas escolhas e decisões regulatórias.......................197

IV. AS DICAS PARA MEMBROS DAS PRÓPRIAS AGÊNCIAS ......................199

1. Descumpram contratos e frustrem a segurança jurídica ..199

2. Não liguem muito para procedimentos .................................201

3. Negligenciem a importância da difusão informacional .....203

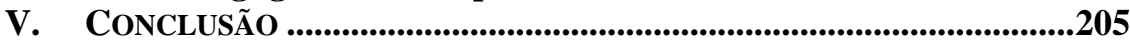

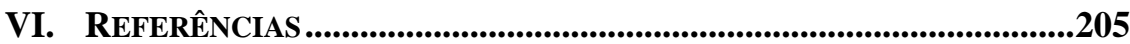

\section{TABLE OF CONTENTS:}

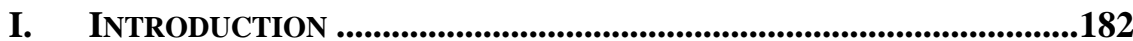

II. THE TIPS TO THE HEAD OF THE EXECUTIVE BRANCH.....................183

1. Weaken the agency's board .................................................183

2. Harm the agency's functioning................................................186

3. Expose agency's decisions to every sort of control...............190

III. THE TIPS TO CONTROLING ENTITIES.............................................193

1. Limit the range of available powers and instruments of agencies.

2. Use the power of punishment to frighten the agencies's employee ...........................................195

3. Interfere with the regulatory choices and decisions.............197

IV. THE TIPS TO THE AGENCIE'S MEMBERS THEMSELVES.....................199

1. Desobey contracts and frustrate the legal certainty............199

2. Do not care too much for the procedures .............................201

3. Neglect the importance of diffunding information .............203

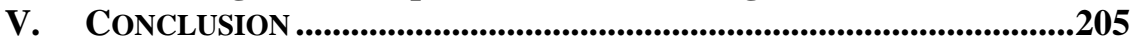

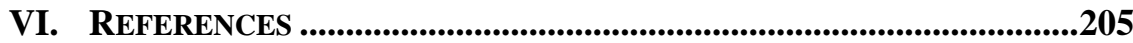




\section{INTRODUÇÃO}

O direito administrativo brasileiro foi inundado, na década de 90 e no início dos anos 2000, de artigos e livros que defendiam a conveniência de instalar agências reguladoras e que explicavam como fazê-lo ${ }^{1}$. Estas produções acadêmicas valiam-se da experiência estrangeira e apontavam as características que estas figuras deveriam ter para assegurar o sucesso do Estado Regulador brasileiro: os mandatos fixos, as indicações técnicas, o isolamento da política, entre outros. Estes textos serviram de guia para os políticos e técnicos envolvidos na Reforma do Estado e foram fontes de informação fundamentais para o desenvolvimento deste projeto.

Poucos anos depois do estabelecimento destas estruturas, no entanto, outros atores institucionais, contrariados, buscaram esvaziá-las e começaram a empreender diferentes técnicas para atingir este objetivo. Acontece que, nesta segunda fase, estas ações públicas se deram de forma desorganizada, descoordenada e pouco informada. Ninguém se preocupou em criar o guia que explicasse os passos a serem seguidos ou agrupasse as melhores práticas para realizar estes objetivos destrutivos. E precisamente este espaço que este artigo pretende preencher. Ao invés de ações experimentais e tentativas, os atores institucionais interessados em prejudicar as agências reguladoras passam a contar com um repositório de estratégias já testadas e bem sucedidas. Basta repeti-las para obter resultados semelhantes ou ainda mais significativos.

A experiência mostra que um tal repositório tem público garantido. Este texto mesmo está voltado diretamente para este público, inclusive na sua estrutura. Cada uma das três partes seguintes é destinada a uma audiência específica. A primeira delas traz dicas para os Chefes do Poder Executivo de diferentes níveis federativos: prefeitos, governadores e

${ }^{1}$ Cf., p. ex., CONFORTO, Glória. Descentralização e Regulação da Gestão de Serviços Públicos. Revista de Administração Pública - RAP, Vol. 32, 1, 1998, p. 27-40;

AZEVEDO, Eurico de Andrade. Agências Reguladoras. Revista de Direito Administrativo - RDA, No. 213, 1998, p. 141-148; SOUTO, Marcos Juruena Villela. Agências reguladoras. Revista de Direito Administrativo - RDA, No. 216, 1999, p. 125-162; SUNDFELD, Carlos Ari. Introdução às Agências Reguladoras. In: Carlos Ari Sundfeld (Org.). Direito Administrativo Econômico. São Paulo, SP: Editora Malheiros/SBDP, 2000, p. 17-38; ARAGÃO, Alexandre dos Santos. As Funções e a Posição das Agências Reguladoras Independentes no Estado Contemporâneo. Dissertação (Mestrado em Direito), Universidade do Estado do Rio de Janeiro, Rio de Janeiro, 2001; JUSTEN FILHO, Marçal. O Direito das Agências Reguladoras Independentes. São Paulo, SP: Dialética, 2002. 
presidente da república. A segunda parte está voltada aos múltiplos órgãos de controle: juízes, tribunais de contas, controladoria e congresso. A terceira e última parte cuida de estratégias de autoflagelo. Explica aos próprios membros das agências reguladoras o que eles podem fazer para dar a sua parcela de contribuição para o ocaso destas entidades. A estrutura é didática e permite ao interessado que salte diretamente para as dicas que lhes concerne. Vamos a elas.

\section{As dicAs PaRA os Chefes dos Poderes ExeCUTIVOS}

As primeiras dicas são endereçadas aos chefes dos poderes executivos. Pudera: para vocês ${ }^{2}$, as agências reguladoras são um grande aborrecimento. Boa parte do poder que tinham foi transferido para elas. Disseram que seria para tornar mais técnica e menos política a regulação de setores de infraestrutura, e assim atrair para eles importantes investimentos privados. Mas o resultado é que você já não pode mais alterar livremente as tarifas das telecomunicações ou de energia elétrica, por exemplo, para controlar artificialmente a inflação ou fazer um agrado nos seus eleitores. Além disso, acaba dividindo com as agências pelo menos parte das decisões relativas ao setor regulado. Mas é possível reagir de pelo menos três formas: (i) enfraqueça o corpo diretor das agências; (ii) prejudique a sua operação; e (iii) exponha as suas decisões a todo tipo de controle.

\section{Enfraqueça o corpo diretor das agências reguladoras}

A primeira e mais óbvia dica para enfraquecer as agências reguladoras consiste em atacar o seu corpo dirigente. Sim, nós sabemos, vão lhe dizer que não dá, porque de acordo com a lei os dirigentes das agências reguladoras possuem mandatos e não poderiam ser demitidos. ${ }^{3}$

2 Como o texto é informal, o pronome de tratamento utilizado também será informal.

${ }^{3}$ A Lei no 9.986/2000, sobre a gestão de recursos humanos nas agências reguladoras, protege os mandatados dos diretores e conselheiros das agências federais em seu art. 9o, o qual dispõe: "Art. 9o Os Conselheiros e os Diretores somente perderão o mandato em caso de renúncia, de condenação judicial transitada em julgado ou de processo administrativo disciplinar." - vedando em teoria sua exoneração imotivada. Outras leis criadoras das agências federais também possuem disposições específicas sobre a estabilidade de mandato, como a Lei no 9.782/1999, sobre ANVISA, em seu art. 12, que protege a estabilidade após 4 meses no cargo; a Lei nº 9.991/2000, sobre a ANS, em seu 
Com um pouco de criatividade, no entanto, dá pra fazer, sim. Uma técnica interessante consiste em utilizar-se da imprensa para pressionar dirigentes indesejados. A estratégia já foi utilizada pelo ex-presidente Luiz Inácio Lula da Silva, logo que iniciou o seu primeiro governo. Desapontado com a intenção do então presidente da ANATEL, Luiz Guilherme Schymura, de respeitar os contratos com as concessionárias do serviço de telecomunicações e aplicar o reajuste de tarifas ali previsto, o ex-presidente passou a se manifestar na imprensa, juntamente com o seu então Ministro das Comunicações, Miro Texeira, contra o dirigente, que havia sido nomeado por Fernando Henrique Cardoso. ${ }^{4}$ A técnica foi bem sucedida: alguns meses depois, Schymura renunciou ao seu mandato. ${ }^{5}$

A vacância do cargo de um dos dirigentes (como resultado desta pressão ou pelo simples fim do mandato) é uma boa oportunidade para loteá-lo com dirigentes com perfil político e sem nenhuma experiência na

art. $8^{\text {o}}$; e a Lei no $11.182 / 2005$, sobre a ANAC, em seu art. 14, caput. As agências reguladoras estaduais também costumam trazer em sua lei de criação disposições neste sentido, como o art. 11 da Lei Complementar Estadual de São Paulo no 914/2002, que criou a ARTESP, e o art. 13 da Lei Estadual do Rio de Janeiro no ${ }^{\circ} .555 / 2005$, que criou a AGETRANSP.

${ }^{4}$ Em reportagem da Folha de São Paulo de 06.01.2004, coloca-se que "Lula começou a negociar com Schymura para que ele deixe a presidência da agência de forma pacífica, segundo apurou a Folha. Desde 2003, Miro [Teixeira] vem trabalhando junto a Lula pela saída de Schymura da Anatel." (...) e "Desde o início do governo, Schymura entrou em rota de colisão com Miro. Em junho, o ministro e Schymura travaram disputa nos bastidores sobre reajuste de empresas de telefonia. (...) A partir desse episódio, Miro trabalha pela derrubada de Schymura. O governo quer evitar que ele peça demissão e entregue o cargo, o que poderia gerar consequências negativas para o governo, na avaliação de Lula." Disponível em:

$<$ http://www1.folha.uol.com.br/folha/dinheiro/ult91u78863.shtml >. Acesso em: $08 \mathrm{de}$ agosto de 2017. Vide também reportagem do jornal Estado de São Paulo, de 25/03/2003, tratando de críticas do ex-Ministro das Comunicações à ANATEL e seu diretor-presidente. Disponível em:

$<$ http://www.estadao.com.br/noticias/geral,ministro-culpa-anatel-por-monopolio-natelefonia,20030325p43262>. Acesso em: 16 de maio de 2017.

${ }^{5}$ Luiz Guilherme Schymura saiu da ANATEL em 06/01/2004, depois de ter sido efetivamente demitido do cargo de presidente, este sim demissível ad nutum; o seu mandato como diretor iria até novembro de 2005. O seu lugar na presidência da agência foi ocupado por Pedro Jaime Ziller, então Diretor da ANATEL desde dezembro de 2003, e que foi o primeiro indicado por Lula em sua presidência. 
área. Um estudo recente da FGV/SP mostra que, em apenas 58\% dos casos, os indicados possuem trajetória profissional relacionada à área de atuação da agência. ${ }^{6}$ Em $90 \%$ dos casos, eles têm perfil estatal. Só $6 \%$ dos nomeados vêm da iniciativa privada. Somente $10 \%$ dos dirigentes nunca tinham exercido qualquer cargo em comissão antes da nomeação. Isto significa que a nomeação de dirigentes com perfil político e/ou sem experiência na área não apenas é uma estratégia já testada, como é mesmo a regra no governo federal ao longo dos 20 anos desde a criação das grandes agências nos setores de infraestrutura. Se você é Chefe do Poder Executivo estadual ou municipal, dizer que está seguindo uma prática já realizada no Governo Federal é um argumento sem par.

Antes de realizar estas nomeações definitivas, há estratégias adicionais que podem ser implantadas. Para começar, não tenha pressa: assegure-se de deixar as agências por alguns meses sem diretores. Isso gerará uma paralisia decisória, já que, por algum período (na média atual, a vacância é de 6 meses $^{7}$ ), as agências não terão o quórum mínimo que a lei exige para a tomada de algumas medidas. No mais, deixe as vacâncias dos cargos de diretoria acumularem para fazer as nomeações definitivas em bloco - 2 ou 3 dirigentes de uma só vez. Isto esvaziará o mecanismo dos mandatos escalonados, estabelecido como forma de moderar o impacto de um governo específico no perfil destas supostas entidades de Estado. Por fim, nomeie, por Decreto, diretores interinos, demissíveis a qualquer tempo. Você terá sempre um excelente argumento para isso: o Congresso, composto na sua visão, por um conjunto de irresponsáveis -

${ }^{6} \mathrm{O}$ estudo empírico apurou que "A expertise técnica dos dirigentes é em muitos casos questionável. Foi realizada uma análise curricular de todos os dirigentes das agências selecionadas. Constatou-se que apenas 58\% têm trajetória profissional conexa com a função de dirigente da Agência Reguladora. Há relação com a trajetória profissional ao cargo de direção quando o dirigente tenha dedicado parcela substancial de sua experiência profissional ao tema relacionado com a função da agência ao qual foi nomeado", em sumário executivo da pesquisa SALAMA, Bruno Meyerhof; BARRIONUEVO, Arthur; PALMA, Juliana Bonacorsi de; DUTRA, Pedro. Processo de Nomeação de Dirigentes das Agências Reguladoras: uma Análise Descritiva. 2016, p. 04. Disponível em:

$<$ https://direitosp.fgv.br/sites/direitosp.fgv.br/files/arquivos/GRP arquivos/sumario ex ecutivo grp - pep 01.pdf $>$. Acesso em: 16 de maio de 2017.

${ }^{7}$ Cf. SALAMA, Bruno Meyerhof; BARRIONUEVO, Arthur; PALMA, Juliana Bonacorsi de; DUTRA, Pedro. Processo de Nomeação de Dirigentes das Agências Reguladoras: uma Análise Descritiva. 2016, p. 04. Disponível em:

$<$ https://direitosp.fgv.br/sites/direitosp.fgv.br/files/arquivos/GRP arquivos/sumario ex ecutivo grp - pep 01.pdf $>$. Acesso em: 16 de maio de 2017. 
ou como disse recentemente um Ministro da Educação ${ }^{8}-$, de achacadores e chantagistas, não quer sabatinar e aprovar os seus indicados para as vagas de diretor das agências. ${ }^{9}$ Sem os diretores, como dito acima, a agência fica paralisada. Como você precisa de decisões da agência para dar cabo da sua agenda política, então, nada mais natural que nomear pessoas que possa demitir, a qualquer tempo, se não fizerem o que lhe convém.

É verdade que as estratégias acima contrariam as leis de cada uma das agências. Mas não se preocupe: estas leis não preveem nenhuma espécie de sanção ou de limites para estes comportamentos. E, como visto, você nem terá sido o primeiro a adotá-los.

\section{Prejudique a operação da agência}

A segunda dica consiste em prejudicar a operação cotidiana das agências. Isso pode ser feito por pelo menos duas vias: (i) as restrições orçamentárias e (ii) as limitações à sua capacidade de contratação de quadros.

Em relação à primeira via, sabe-se que, em teoria, a possibilidade de interferir no orçamento das agências estaria afastada, pois o próprio

${ }^{8}$ Declaração que o ex-Ministro da Educação Cid Gomes proferiu, em 27/02/2015, em visita à Universidade Federal do Pará, afirmando que a Câmara dos Deputados possui de 300 a 400 parlamentares achacadores e chantagistas. Chamado à Câmara dos Deputados para explicar sua fala em 18/03/2015, ele repetiu sua declaração em Plenário, resultando em disputa com o então presidente da casa Eduardo Cunha e outros deputados, que culminou na sua saída do Ministério da Educação. Disponível $\mathrm{em}$ : $<$ http://congressoemfoco.uol.com.br/noticias/cid-gomes-nao-e-mais-ministro-dizcunha>. Acesso em: 08 de agosto de 2017.

${ }_{9}^{9}$ Vide as seguintes reportagens: a primeira é do Estado de São Paulo de 17/02/2014, relatando que a ANTT e ANTAQ estavam com a diretoria incompleta, ocupadas por diretores interinos e com risco de ficar sem comando. Disponível em:

$<\underline{\text { http://economia.estadao.com.br/noticias/geral,agencias-reguladoras-de-transporte- }}$ correm-risco-de-ficar-sem-comando,178005e >. Acesso em: 08 de agosto de 2017. Já a segunda, do O Globo de 26/01/2016, retrata a persistência da utilização de diretores internos e da ocorrência de desfalques, expondo que cinco das dez agências aparentavam ao menos um desses problemas categorias. Disponível em: $<$ https://oglobo.globo.com/brasil/metade-das-agencias-reguladoras-federais-estadesfalcada-15148787>. Acesso em: 08 de agosto de 2017. 
conceito de entidade independente suporia sua autonomia financeira. ${ }^{10}$ As agências seriam autossustentáveis, mediante cobrança de taxas de fiscalização, multas, outorgas dos seus regulados, e teriam orçamentos independentes dos ministérios aos quais estão vinculadas. ${ }^{11}$ Acontece que, no âmbito da União, desde o governo Fernando Henrique Cardoso, o "Princípio da Unidade Orçamentária" tem sido interpretado como exigência de que todos os recursos arrecadados pela agência voltem para

${ }^{10}$ Vide, por exemplo, o art. 8o $\S^{2}{ }^{\circ}$ da Lei no 9.472/1997, sobre a ANATEL, o qual estabelece como integrante da independência das agências a autonomia financeira " $\$ 2$ " A natureza de autarquia especial conferida à Agência é caracterizada por independência administrativa, ausência de subordinação hierárquica, mandato fixo e estabilidade de seus dirigentes e autonomia financeira." As outras leis criadoras de agências possuem artigos com o mesmo teor. No mesmo sentido, Marçal Justen Filho aponta como característica essencial do "regime jurídico que assegura autonomia em face da Administração Direta", o "regime de autonomia econômico-financeira, por meio de receitas próprias destinadas a adotar meios para o desempenho de suas funções", em JUSTEN FILHO, Marçal. Curso de Direito Administrativo. 12ª ed. São Paulo, SP: Editora Revista dos Tribunais, 2016, p. 538-539.

${ }^{11}$ Desde o início da reflexão na doutrina sobre agências reguladoras, já se coloca com importância a autonomia orçamentária e sua sustentabilidade pela cobrança de taxas próprias, conforme explicado por Marcos Juruena Villela Souto em artigo de 1999: “A fim de garantir a autonomia das agências reguladoras, definidas no Brasil como autarquias especiais, se estabeleceu mecanismo de atribuição de receitas sem que os recursos tenham que transitar pelo Erário; foi instituída uma 'taxa de regulação' ou 'taxa de fiscalização dos serviços concedidos ou permitidos' , devida pelo concessionário ou permissionário de serviços diretamente à agência; calcula-se o valor da taxa com base em percentual sobre o proveito obtido com a concessão ou permissão. A agência, com isso, não depende de recursos orçamentários, mas, em compensação, se submete à crítica de ser custeada pelo sujeito fiscalizado." SOUTO, Marcos Juruena Villela. Agências reguladoras. Revista de Direito Administrativo RDA, No. 216, 1999, p. 125-162. Tal objetivo fica claro nas disposições normativas, p. ex. Lei no 9.661/2000, sobre a ANS, a qual estabelece as fontes de receita desta agência em seu art. 17, incluindo a previsão da Taxa de Saúde Suplementar (espécie do gênero taxa de regulação), a qual deverá ser recolhida em conta vinculada à ANS (art. 23). Igualmente, a Lei $\mathrm{n}^{\mathrm{o}}$ 10.233/2001, sobre a ANTT e a ANTAQ, em seu art. 77, institui a cobrança de taxas de fiscalização. Já o art. 78 da lei confere-lhes prerrogativa de submeter suas próprias propostas orçamentárias anuais a, respectivamente, o Ministério dos Transportes e a Secretaria de Portos da Presidência. 
a conta única da União. ${ }^{12}$ Assim, ficam dependentes de realocação orçamentária para retornar à agência. Está aí a oportunidade para barrar esta transferência. Basta prever, nas rubricas destinadas às agências na proposta de orçamento anual, - que em tese lhes devolveria, por meio da alocação orçamentária anual os valores que arrecadou no último ano montantes menores que os arrecadados.

Em relação a esse tema, é bem provável que o Congresso siga a sua sugestão e aprove para as agências somente o valor que você sugeriu em sua proposta de Lei Orçamentária Anual. Não há o que se preocupar quanto a lobbies no Congresso que possam mexer nesse assunto. Ninguém quer uma agência forte. Os regulados preferem uma agência fraca, para poderem descumprir mais tranquilamente os contratos. Os controladores da Administração também preferem uma agência fraca, para substituírem mais facilmente as suas decisões e ocuparem os seus espaços. Então, é quase garantido que a sua proposta de alocação orçamentária à agência será atendida pelo Congresso. Depois disso, você ainda poderá contingenciar esses recursos. Segundo levantamento da entidade Contas Abertas, entre 2010 e 2015, anos do Governo de Dilma Rousseff, o orçamento total previsto para as agências era de $\mathrm{R} \$ 57$ bilhões. No entanto, apenas $R \$ 19,3$ bilhões foram efetivamente liberados e gastos..$^{13} \mathrm{Em}$ 2016, a ANEEL havia estimado orçamento de $\mathrm{R} \$ 200$ milhões. O Governo aprovou a metade: $\mathrm{R} \$ 100$ milhões. Na sequência, dois Decretos reduziram ainda mais o valor: primeiro para $\mathrm{R} \$ 90$ milhões e depois para $R \$ 44$ milhões - ou seja, menos de um quarto do valor inicialmente proposto pela agência e cerca de um décimo do que a própria

${ }^{12}$ A Lei no 4.320/1964, que estabelece as normas gerais de Direito Financeiro, estabelece este princípio no seu art. $2^{\circ}$, o qual dispõe que "Art. $2^{\circ}$ A Lei do Orçamento conterá a discriminação da receita e despesa de forma a evidenciar a política econômica financeira e o programa de trabalho do Governo, obedecidos os princípios de unidade, universalidade e anualidade." Conforme definição do Senado Federal, o Princípio da Unidade Orçamentária é aquele "segundo o qual os orçamentos de todos os órgãos que constituem o setor público devem fundamentar-se segundo uma única política orçamentária, estruturam-se uniformemente e ajustarem-se a um método único". Disponível em: $<$ https://www12.senado.leg.br/orcamento/glossario/principio-daunidade-do-orcamento $>$. Acesso em: 08 de agosto 2017.

${ }^{13}$ Cf. artigo no site da Contas Abertas, datado de 29/08/2016. Disponível em: $<$ http://www.contasabertas .com.br/website/arquivos/13576>. Acesso em: 08 de agosto 2017. 
agência arrecadara no ano anterior. ${ }^{14}$ No caso da ANEEL, o orçamento terminou por ser reestabelecido para $\mathrm{R} \$ 120$ milhões $^{15}$; mas com o contingenciamento, as agências precisaram cortar gastos e até mesmo descontinuar serviços e atividades essenciais, como a fiscalização dos serviços. Foi o que aconteceu recentemente com ANAC, ANATEL e ANEEL. 16

Já no que concerne à segunda via para prejudicar a operação das agências, o ideal é limitar no seu Ministério ou Secretaria de Planejamento todas as contratações de pessoal, negando às agências a independência administrativa, impedindo-as de selecionar e contratar seus próprios quadros. Se você estiver de fato seguindo o nosso conselho em relação ao contingenciamento de recursos, isso não será difícil de fazer. Com escassez de recursos para manter as suas atividades, a agência terá todo incentivo para aceitar que o Ministério ou Secretaria de Planejamento

${ }^{14} \mathrm{O}$ primeiro corte de gastos foi anunciado, em 19/02/2016, no valor de $\mathrm{R} \$ 23,4$ bilhões, e o segundo corte de gastos foi, em 22/03/2016, no valor de $\mathrm{R} \$ 21,2$ bilhões, para buscar cumprir a meta de superávit primário. Disponível em:

$<\underline{\text { http://www12.senado.leg.br/noticias/materias/2016/06/15/diretor-geral-da-aneel- }}$ defende-autonomia-financeira-para-agencias-reguladoras $>$. Acesso em: 08 de agosto 2017.

${ }^{15}$ Disponível em: <http://g1.globo.com/economia/noticia/2016/06/aneel-retomaservicos-cortados-apos-orcamento-subir-r-120-milhoes.html>. Acesso em: 08 de agosto 2017.

${ }^{16}$ Sobre os cortes no orçamento da na ANEEL, Disponível em: $<$ http://g1.globo.com/economia/noticia/2016/05/aneel-suspende-atendimento-aoconsumidor-apos-corte-no-orcamento.html>. Acesso em: 08 de agosto 2017. Na ANATEL, Cf. reportagem de 11/10/2016, na qual é colocado que "A redução do orçamento chama mais a atenção se considerados os valores arrecadados pela agência. Só em 2015, a Anatel levantou R \$ 5,4 bilhões com o Fundo de Fiscalização das Telecomunicações (Fistel) - que inclui o valor arrecadado no leilão da frequência de $700 \mathrm{MHz}$ - e R\$2,2 bilhões por meio do Fundo de Universalização das Telecomunicações (Fust). 'A maior parte foi repassada ao Tesouro', diz Quadros." Disponível em: $<$ http://link.estadao.com.br/noticias/empresas, corte-de-orcamento-edesafio-na-anatel-diz-novo-presidente,10000081409>. Acesso em: 08 de agosto 2017. E na ANAC, o corte de recursos foi um dos responsáveis, em 2006, pela grande crise no setor seguindo a queda do Voo Gol 1907, que foi denominada de "apagão aéreo" - e os problemas continuam até hoje. Disponível em:

<http://painel.blogfolha.uol.com.br/2016/01/01/com-orcamento-menor-anac-tera-queoptar-entre-corte-na-fiscalizacao-ou-na-operacao-olimpica/>. Acesso em: 08 de agosto 2017. 
conduza o concurso público, o treinamento dos seus agentes e que se comprometa, por essa via, a destinar, nas alocações orçamentárias anuais para a agência, os recursos para cobrir as despesas com a contratação desses novos quadros. Na verdade, ela se achará privilegiada por receber esse tratamento do Governo, já que, com recursos limitados, ela não poderia arcar com essas atividades.

\section{Exponha as decisões das agências a todo tipo de controle}

As medidas de esvaziamento interno das agências acima recomendadas são relevantes e eficazes, mas não são suficientes. É preciso garantir também um ataque externo, para assegurar a sua desestabilização completa. Neste sentido, táticas adequadas podem consistir (i) na abertura de espaços de controle supostamente indisponíveis e (ii) no favorecimento ou na ampliação da intervenção de controladores já atuantes.

Como exemplo do primeiro caso, há precedente na criação do chamado "recurso administrativo hierárquico impróprio", para permitir a revisão das decisões das agências pelos ministérios aos quais elas estão vinculadas. Em tese, estas decisões das agências deveriam estar imunes a qualquer revisão no âmbito do Poder Executivo. ${ }^{17}$ Mas, em 2005, o Ministério dos Transportes acolheu um recurso hierárquico e modificou decisão da ANTAQ sobre a legalidade da cobrança, por operadores portuários, de uma taxa chamada THC2, sobre a movimentação e entrega de contêineres destinados a outros recintos alfandegados. ${ }^{18}$ Diante da

${ }^{17}$ Cf. “[o]s atos da agência reguladora independente não se sujeitam à revisão por autoridade integrante da Administração direta, mas apenas perante o Poder Judiciário". JUSTEN FILHO, Marçal. Curso de Direito Administrativo. 12ª ed. São Paulo, SP: Editora Revista dos Tribunais, 2016, p. 539; e "como autarquias de regime especial, seus atos não podem ser revistos ou alterados pelo Poder Executivo. A estabilidade outorgada aos dirigentes das agências confere maior independência, não muito comum na maior parte das entidades da Administração Indireta, em que os dirigentes, por exercerem cargos de confiança do Chefe do Poder Executivo, acabam por curvar-se a interferências, mesmo que ilícitas." DI PIETRO, Maria Sylvia Zanella. Direito Administrativo. 30ª ed. Rio de Janeiro, RJ: Forense, 2017, p. 604-605. A decisão em último grau das agências também é estabelecida legalmente, Cf., p. ex., o art. 19, XXV da Lei no 9.472/1997 (ANATEL).

18 Processo administrativo ANTAQ no 50300.000022/02. Neste processo, a ANTAQ decidiu, pela maioria de seus Diretores, que a cobrança de taxa pelos operadores 
polêmica que se instalou, a AGU emitiu parecer (depois aprovado pelo ex-presidente Lula), tendo o cuidado de deixar claro que a possibilidade deste recurso era "excepcional". ${ }^{19}$ Mas esta palavra não deve impressionar. No trecho em que definia as circunstâncias que autorizariam esta revisão excepcional, a AGU teve o cuidado ainda maior de fazer uso daquelas palavras abstratas e genéricas que deixam as portas bem abertas para a intervenção dos Ministérios, quando julgarem conveniente..$^{20}$ No aperto, não se esqueça: a porta segue aberta. Nos Estados e Municípios, o exemplo da União é sempre seguido mimeticamente. Se algo foi feito no âmbito da União, geralmente não é preciso grande justificativa para um agente público estadual ou municipal repetir o mesmo ato no seu respectivo ente governamental.

Como exemplo do segundo caso, instrua as mais variadas agências a submeter voluntariamente os seus projetos de decisões aos controladores. Isso mesmo: explique às agências que, durante o seu governo, antes de decidir qualquer coisa, elas devem pedir a benção dos órgãos de controle. Justifique isso com palavras bonitas. Diga que é preciso haver uma "aproximação" entre reguladores e controladores. Diga que eles precisam trabalhar em equipe. Que precisam "conversar". Quem, afinal, é contra um bom bate papo? O recém-empossado governo Temer já deu um grande passo nesta direção. Determinou que todos os editais de licitação das concessões do programa de parceria de investimentos sejam submetidos previamente para aprovação do Tribunal de Contas da União

portuários sobre a movimentação e entrega de contêineres a outros recintos alfandegários no Porto de Salvador - a taxa TCH2 (terminal handling charge) apresenta indícios de uma exploração abusiva de posição dominante dos operadores portuários, dado que esses serviços já estariam abrangidos pela taxa THC1. Assim, decidiu que a cobrança é indevida e remeteu o caso à análise do CADE - Conselho Administrativo de Defesa Econômica. Após o esgotamento de recursos na ANTAQ, a empresa prejudicada apresentou recurso hierárquico impróprio ao Ministério dos Transportes, obtendo do Ministro a reversão da decisão da agência.

19 Parecer AGU AC-051, anexado ao Parecer nº AGU/MS04/2006: Definição acerca dos instrumentos da supervisão ministerial e da possibilidade de provimento de recurso hierárquico impróprio contra as decisões das agências reguladoras. Disponível em: <http://www.agu.gov.br/atos/detalhe/8453>. Acesso em: 08 de agosto 2017.

${ }^{20} \mathrm{O}$ parecer permitiu a apresentação de recurso hierárquico impróprio de decisões das Agências Reguladoras que i) "ultrapassem os limites de suas competências materiais definidas em lei" ou ii) "violem as políticas públicas definidas pelo setor regulado pela Administração Direta" (Ementa do Parecer AC-051). Ambas as hipóteses lidam de conceitos jurídicos indeterminados. Ainda, estabeleceu que controvérsias sobre esses temas devem ser dirimidas pela própria AGU. 
- tal como, aliás, já vinha sendo a prática. ${ }^{21}$ Pouco importa que não haja, no direito brasileiro, qualquer norma de qualquer hierarquia que dê este poder prévio ao TCU. ${ }^{22}$ Pouco importa, aliás, que a inexistência de previsão normativa destes poderes prévios corresponda a uma opção clara do Constituinte brasileiro, desde 1967, de eliminar a atuação preventiva até então existente desta Corte de Contas. ${ }^{23} \mathrm{O}$ que é realmente relevante é que estas conversas prévias abram caminho para que o TCU tome o espaço das agências e atue como efetivo regulador, interferindo diretamente na própria modelagem dos projetos de infraestrutura.

${ }^{21} \mathrm{O}$ "Projeto Crescer" do Governo Federal sob a presidência de Michel Temer, que integra o âmbito do Programa de Parcerias de Investimentos - PPI, foi anunciado em 13/09/2016 juntamente com suas 10 diretrizes. Sua diretriz no 5 coloca que "Os editais só serão lançados depois de passar pelo debate público e obter o aval do TCU”. Disponível em: <http://www.projetocrescer.gov.br/10-diretrizes $>$. Acesso em: $08 \mathrm{de}$ agosto 2017. Em verdade, essa determinação apenas confirma o que já vinha sido praticado pela União, visto que, nos Governos Lula e Dilma, o único projeto de concessão sem aprovação prévia de seus estudos de viabilidade pelo TCU foi o edital de concessão do campo de petróleo de Libra, conforme já observado em RIBEIRO, Maurício Portugal. Comentários às Diretrizes Recentemente Publicadas do Novo Programa de Investimentos em Infraestrutura do Governo Federal. 2016. Disponível em: $<$ http://www.portugalribeiro.com.br/comentarios-as-diretrizes-recentementepublicadas-do-novo-programa-de-investimentos-em-infraestrutura-do-governofederal/>. Acesso em: 08 de agosto 2017.

${ }^{22}$ Cf. JORDÃO, Eduardo. A intervenção do TCU sobre editais de licitação não publicados: controlador ou administrador? Revista Brasileira de Direito Público RBDP, Vol. 12, 47, 2014, p.209-230. Neste artigo, uma das conclusões foi de que o TCU "não pode exigir a apresentação de minuta de edital ainda não publicado", e que este "não detém poderes para intervir de forma autorizativa numa medida de edital não publicada. As competências constitucionais explícitas que se atribuíram ao TCU não implicam necessariamente competências implícitas geradoras de um 'poder geral de cautela'.".

${ }^{23}$ Cf. SPECK, Bruno Wilhelm. Inovação e rotina no Tribunal de Contas da União: o papel da instituição superior de controle financeiro no sistema políticoadministrativo do Brasil. São Paulo, SP: Fundação Konrad-Adenauer-Stiftung, 2000; e também COTIAS E SILVA, Arthur Adolfo. O Tribunal de Contas da União na História do Brasil: evolução histórica, política e administrativa (1890-1998). In: TRIBUNAL DE CONTAS DA UNIÃO. Prêmio Serzdello Corrêa 1998: Monografias Vencedoras. Brasília, DF: Tribunal de Contas da União/Instituto Serzdello Corrêa, 1999, p. 19-141. 


\section{AS DICAS PARA OS ÓRGÃOS DE CONTROLE}

Nesta segunda parte, as dicas se destinam aos mais diversos órgãos de controle e apresenta as estratégias que podem ser (e já vêm sendo) implementadas por eles para produzir o enfraquecimento das agências. Aqui também são três as estratégias principais: (i) limitar o leque de ações ou instrumentos à disposição das agências; (ii) amedrontar os seus funcionários; e (iii) interferir nas suas escolhas e decisões concretas. As duas primeiras servem para atrapalhar o funcionamento e a eficiência das agências reguladoras. A terceira, para minar a sua legitimidade.

\section{Limite o leque de ações ou instrumentos à disposição das agências}

Comece por adotar interpretações restritivas do direito, que limitem o leque de ações ou instrumentos à disposição das agências. Assim você prejudica o seu funcionamento e o cumprimento de suas missões institucionais.

Siga o exemplo de vários de seus colegas controladores que resistem ao recurso à arbitragem para solucionar controvérsias entre a administração pública e particulares. ${ }^{24}$ Valha-se do argumento de que os interesses públicos são indisponíveis - e ignore que o interesse público nos setores de infraestrutura pode consistir precisamente na solução mais rápida, técnica e imparcial dos conflitos, garantida pela arbitragem, cujo uso já foi autorizado pela Lei de Concessões e pela Lei de PPP. ${ }^{25}$ Note, afinal, que a disseminação do uso da arbitragem implicaria a redução do seu próprio poder como controlador. Ao viabilizar o acesso a instância alternativa ao Poder Judiciário, apta a dar soluções rápidas e técnicas aos conflitos, abrir-se-ia para os concessionários via para questionar decisões

${ }^{24}$ O principal expoente dessa resistência é o Tribunal de Contas da União, que abriu precedente neste sentido no acórdão 2.573/2012 ao entender ser inaplicável “a arbitragem para resolução de divergências relativas às questões econômico-financeiras do contrato de concessão, haja vista o que dispõe o art. 24, inciso VII, da Lei 10.233/2001". Por causa desta decisão, e por meio de represálias, as agências reguladoras têm oferecido grande resistência à realização de arbitragem para solucionar controvérsias em seus respectivos campos. Disponível em: $<$ https://contas.tcu.gov.br/pesquisaJurisprudencia/\#/>. Acesso em: 08 de agosto 2017. ${ }^{25}$ A Lei no 8.987/1995, sobre concessões, autoriza a realização de arbitragem no seu artigo 23-A (incluído pela Lei oㅜ 11.196/2005) e a Lei oำ11.079/2004, sobre PPPs, autoriza a previsão de arbitragem em seu art. 11, III. 
das agências que seguem determinações emitidas pelos controladores. Na prática, portanto, a arbitragem teria o efeito indireto de dar limites ao poder dos controladores da Administração Pública, que tinham suas decisões protegidas pelo temor de submeter as questões ao Poder Judiciário, em vista da demora para obtenção de decisões definitivas, e das dificuldades de um juiz não especialista em infraestrutura entender as questões técnicas e econômico-financeiras relativas a contratos de concessão ou PPP.

Em seguida, dificulte o recurso das agências à expertise de terceiros. Uma vez que diversas de suas atividades são altamente técnicas e especializadas, faria sentido que as agências tivessem maior flexibilidade que outras entidades na contratação de consultores externos. Ao invés disso, a CGU e o TCU consideraram ilícitos os procedimentos expeditos criados, entre outros fins, para a contratação de consultores pela ANATEL, por meio do procedimento chamado de "Consulta", que tinha previsão específica na Lei Geral de Telecomunicações. ${ }^{26}$ Além disso, tem sido comum que as Leis de Diretrizes Orçamentárias federais e de alguns estados nos últimos anos prevejam que atividades teoricamente realizáveis por agentes públicos não podem ser objeto de contrato de consultoria. ${ }^{27}$ Considere essa regra aplicável às agências e puna os

${ }^{26}$ O TCU decidiu em seu acórdão no 31/51/2011 - Plenário que a ANATEL encontra-se subordinada à Lei no 8.666/1993 para a contratação de objetivos não considerados como comuns (visto que os comuns poderão ser licitados por meio de pregão, regido pela Lei no 10.520/2000), e também que “Anatel somente poderá utilizar-se do regramento sobre licitações contido na Lei Geral de Telecomunicações quando implementar concessão, permissão ou autorização de serviços de telecomunicações e de uso de rádio frequência". Assim, vedou a utilização da consulta para a contratação de bens ou serviços destinados à própria agência.

${ }^{27}$ Por exemplo a Lei de Diretrizes Orçamentárias (LDO) da União de 2017 (Lei n⿳o 13.408/2016), a mais recente no momento de elaboração desde artigo, estabelece essa vedação em seu artigo $18, \S 2^{\circ}$, ao colocar: “Art. 18. Não poderão ser destinados recursos para atender a despesas com: (...) $§ 2^{\circ}$ A contratação de serviços de consultoria, inclusive aquela realizada no âmbito de acordos de cooperação técnica com organismos e entidades internacionais, somente será autorizada para execução de atividades que, comprovadamente, não possam ser desempenhadas por servidores ou empregados da administração pública federal, no âmbito do respectivo órgão ou entidade, publicando-se, no Diário Oficial da União, além do extrato do contrato, a justificativa e a autorização da contratação, na qual constarão, necessariamente, a identificação do responsável pela execução do contrato, a descrição completa do objeto do contrato, o quantitativo médio de consultores, o custo total e a especificação dos 
funcionários de agência que tentarem contratar consultorias para assessorá-las.

Último exemplo: o TCU considerou ilícito o convênio de cooperação entre a EBP - Estruturadora Brasileira de Projetos e o BNDES. ${ }^{28}$ Esse convênio, entre outros efeitos, dava à EBP um tratamento diferenciado nos processos de PMI perante órgãos do Governo Federal. A decisão é uma lição em si: analisa o convênio com base em parâmetros tradicionais do Direito Administrativo, ignorando o funcionamento paraestatal da EBP e o papel único que teve nos últimos anos na viabilização de concessões e PPPs nos mais diversos setores de infraestrutura, inclusive na realização das principais concessões federais de aeroportos e de rodovias.

\section{Usem os poderes de punição para amedrontar os funcionários das agências}

A segunda estratégia que os controladores podem utilizar para atrapalhar o funcionamento das agências é manejar extravagantemente o seu poder de sanção. Há casos exemplares de punição pessoal do TCU a técnicos e diretores das agências reguladoras em que não há sequer suspeita de obtenção de quaisquer benefícios pessoais - apenas decisões contrárias às que os controladores consideram correta. ${ }^{29}$

serviços e o prazo de conclusão." Disposições similares encontram-se em todas as LDOs da União desde 1998, em todos os anos até o presente, inclusive, no caso das LDOs mais recentes, no mesmo art. $18, \S 2^{\circ}$.

${ }_{28}$ TCU, acórdão 1.602/2015 - Plenário. A decisão foi de conferir ao BNDES um prazo de trezentos e sessenta dias para anular o convênio de cooperação técnica com a EBP, e de que durante este prazo a continuidade do convênio estaria restrita à conclusão dos projetos em andamento.

${ }^{29}$ O relatório de acompanhamento do TCU TC-014.689/2014-6, sobre o processo de aprovação da obra denominada Nova Subida da Serra na Concessão da BR-40/MG/RJ, não apenas concluiu ser ilegal a aprovação pela ANTT do $12^{\circ}$ Termo Aditivo, que adicionou esta obra à Concessão, mas também recomendou a responsabilização de diversos agentes públicos envolvidos na aprovação desta obra, especialmente os diretores da ANTT que aprovaram o termo aditivo. A acusação não foi de favorecimento pessoal, mas sim de anuir com celebração de termo aditivo supostamente ilegal, em virtude da qual se almejava responsabilização pessoal dos então agentes, incluindo a aplicação de multas. No acórdão 738/2017, o TCU acolheu as razões de justificativa apresentadas pelos então agentes públicos envolvidos, não os condenando, mas manteve a decisão de anular o termo aditivo da Nova Subida da 
Esta forma de agir gera três circunstâncias relevantes para o enfraquecimento das agências reguladoras. Em primeiro lugar, dificulta o recrutamento de bons quadros para compor o seu pessoal. Afinal, estes profissionais se sentirão desestimulados a ingressar neste cenário e arriscar a sua reputação, a sua liberdade, ou o seu bolso. Em segundo lugar, os funcionários que ultrapassem este desestímulo e venham a compor os quadros das agências estarão apavorados e desconfortáveis para tomar qualquer solução mais criativa ou audaciosa. O relevante passa a ser salvar a própria pele, não pensar em soluções que possam conduzir à realização do interesse público. ${ }^{30}$ Nem é preciso dizer da ineficiência a se esperar de uma entidade dirigida e tocada por funcionários intimidados. Em terceiro lugar e enfim, este uso desmedido do poder de sanção termina funcionando como gatilho para que o controlador possa impor as suas próprias escolhas sobre as do regulador. A ameaça de aplicar sanções, mesmo quando feita de forma sutil, pode fazer o controlador participar ativamente das decisões regulatórias. Assim, o Ministério Público tem "deixado saber" aos vários reguladores, como uma espécie de "sugestão", as suas escolhas e preferências regulatórias antes mesmo de que decisões específicas tenham sido tomadas. Outras vezes, é o próprio regulador quem, amedrontado, "consulta" o controlador sobre decisão que pretende tomar. No caso do edital de concessão do Aeroporto do Galeão, o TCU sugeriu alterações nas minutas de editais não publicadas. O TCU justificou esta atuação, que não possui base normativa específica, com o argumento de que seria melhor para a própria administração pública que atuasse previamente, já que tinha poderes de sanção e de sustação posteriores à publicação. Em bom português, "é melhor seguir o nosso conselho logo agora". Isso, aliás, não é novidade. Em vários casos, o TCU tem se manifestado sobre minutas de editais e contratos de concessão previamente à sua

Serra. A decisão final do plenário isentou de responsabilidade todos os agentes públicos envolvidos.

${ }^{30}$ Sobre a questão, Cf. artigo de Carlos Ari Sundfeld, no qual coloca que “O gestor tem de ser protegido contra os excessos de fiscalização. Do contrário, morrendo de medo de algum processo, ele cruza os braços e fica esperando a aposentadoria chegar." SUNDFELD, Carlos Ari. Chega de Axé no Direito Administrativo. Disponível em: $<$ http://www.sbdp.org.br/ artigos ver.php?idConteudo=100 $>$. Acesso em: 08 de agosto de 2017. Cf. também GUIMARÃES, Fernando Vernalha. O Direito Administrativo do Medo: a crise da ineficiência pelo controle. 2016. Disponível em:

<http://www.direitodoestado.com.br/colunistas/fernando-vernalha-guimaraes/odireito-administrativo-do-medo-a-crise-da-ineficiencia-pelo-controle $>$. Acesso em: 08 de agosto de 2017. 
publicação. Isso porque os reguladores, temerosos das decisões do TCU, enviam-lhe esses documentos previamente à sua publicação. ${ }^{31}$

\section{Interfira nas escolhas e decisões regulatórias}

Uma das técnicas que você, controlador, pode utilizar para interferir nas escolhas das agências reguladoras já foi adiantada acima: usar o poder de sanção em uma mão e as suas "meras sugestões" na outra. Mas há pelo menos duas outras que são bastante bem sucedidas.

A primeira consiste em ignorar a complexidade do direito e a absoluta ausência de "respostas corretas" (ou "únicas respostas lícitas") para várias das questões que devem ser resolvidas pelas agências reguladoras - e impor a sua solução de preferência, sob o argumento de que ela é exigida pelo direito. Em vários países, o reconhecimento da realidade complexa levou tribunais a criarem doutrinas de deferência às soluções escolhidas pelas entidades reguladoras: na ausência de uma resposta préconcebida pelo direito a problemas específicos, caberia a elas optar por uma dentre as várias decisões abstratamente lícitas. ${ }^{32}$ Entre nós, juízes e tribunais têm resistido a dar este voto de confiança ao regulador. Ao invés disso, costumam impor as suas próprias soluções, muitas vezes a partir do que supõem que um princípio abstrato necessariamente exigiria diante de um caso concreto qualquer. ${ }^{33}$ Eis um caminho a se seguir. $\mathrm{O}$ princípio da dignidade humana sozinho, por exemplo, lhe abrirá um mundo de possibilidades.

A segunda técnica para interferir nas decisões das agências reguladoras consiste em realizar um esgarçamento (ou uma

${ }^{31}$ Sobre o tema, cf. JORDÃO, Eduardo. A intervenção do TCU sobre editais de licitação não publicados: controlador ou administrador? Revista Brasileira de Direito Público - RBDP, Vol. 12, 47, 2014.

32 Uma análise completa sobre o tema encontra-se em JORDÃO, Eduardo. Controle Judicial de uma Administração Pública Complexa: a experiência estrangeira na Adaptação da Intensidade do Controle. São Paulo, SP: Malheiros/SBDP, 2016.

${ }_{33}$ A Resolução ANAC no 400/2016, que passou a permitir a cobrança pelo despacho de bagagem foi suspensa, liminarmente, em 13/03/2017, pelo juiz José Henrique

Prescendo, da 22 ${ }^{a}$ Vara Cível Federal de São Paulo. Disponível em:

$<$ http://s.conjur.com.br/dl/decisao-jf-sp-anac-bagagem.pdf $>$. Acesso em: 08 de agosto de 2017. Sobre o caso, que é representativo do tipo de intervenção judicial que ocorre sobre a ação das agências reguladoras, cf. JORDÃO, Eduardo. Cobrança por bagagem: o que diz o Direito? Disponível em: $<$ https://jota.info/colunas/ supra/cobranca-porbagagem-o-que-diz-o-direito-24032017>. Acesso em: 08 de agosto de 2017. 
"interpretação criativa") de suas próprias competências de controle. Tome-se o caso do Congresso. A Constituição lhe permite sustar atos normativos do Poder Executivo "que exorbitem do poder regulamentar ou dos limites da delegação legislativa". ${ }^{34}$ Mas o dispositivo tem sido usado para afastar regras técnicas impopulares ou regras com as quais o Congresso simplesmente não concorda. Assim se deu em 2014, quando o Congresso editou Decreto Legislativo para sustar a eficácia de resolução da ANVISA que vedava a comercialização de medicamentos inibidores de apetite usados contra a obesidade..$^{35}$ Mais recentemente, o Senado já aprovou o Decreto Legislativo que afastará a resolução da ANAC que liberava a cobrança, pelas companhias aéreas, de bagagens despachadas em voos domésticos. ${ }^{36}$ Há exemplos também do TCU, que costuma se valer dos processos de tomada de contas especial para alterar aspectos regulatórios de contratos de concessão em curso. Em relação aos contratos da 1 $1^{\underline{a}}$ Etapa do Programa de Concessões de Rodovias Federais - PROCOFE, a Corte de Contas exigiu da ANTT a adoção da metodologia do reequilíbrio econômico financeiro por fluxo de caixa marginal para a inclusão de novos investimentos nesses contratos. ${ }^{37}$ Este exemplo, aliás, é ótimo para mostrar a eficácia das intervenções do controlador. É que aqui se trata de uma medida que não poderia ter sido tomada nem mesmo pela agência isoladamente - a Lei de Licitações exige o assentimento dos concessionários para alteração de regras econômico-financeiras de contratos em curso.

${ }^{34}$ Art. 49, V, da Constituição Federal.

${ }^{35}$ Assim se deu em 2014, quando o Congresso editou Decreto Legislativo no 273/2014, publicado em 05/09/2014, para sustar a eficácia de resolução da ANVISA que vedava a comercialização de medicamentos inibidores de apetite usados contra a obesidade.

36 O Senado aprovou, no final de 2016, o projeto de decreto legislativo PDS no 89/2016, que susta a resolução da ANAC autorizativa da cobrança pelo despacho de bagagens em voos domésticos. Atualmente, este decreto está em fase de análise pela Comissão de Defesa do Consumidor da Câmara dos Deputados, na qual tramita como PDC no 578/2016, tendo recebido parecer favorável do relator nesta comissão. Sobre o tema, cf. JORDÃO, Eduardo; LARDOSA, Arthur. Congresso x Agências: limites, só para os outros. Disponível em: < $\underline{\text { https://jota.info/colunas/supra/congresso-x-agencias-limites- }}$ para-os-outros-19122016>. Acesso em: 08 de agosto de 2017.

${ }^{77}$ Decisão adotada pelo TCU no Plenário, Acórdão n 2.154/2007, (Ata no 42/2007), rel. Min. Ubiratan Aguiar, j. 10.10.2007, com diversos desdobramentos, inclusive o TCU, Plenário, Acórdão n 1.055/2011 (Ata nํ14/2011), rel. Min. Walton Alencar Rodrigues, j. em 24.07.2011. 
Mas você, controlador, não precisa se preocupar com estes detalhes. No direito brasileiro, os controladores são muito pouco controlados - e todas as estratégias acima deverão ser (e já vêm sendo) muito eficazes.

\section{AS DICAS PARA MEMBROS DAS PRÓPRIAS AGÊNCIAS}

Um texto com dicas para desestruturar as agências reguladoras não poderia deixar de trazer estratégias de autoflagelo. Normalmente, os integrantes destas entidades supõem que o seu ocaso é culpa de terceiros, políticos e/ou controladores néscios ou sedentos de poder. Nunca admitem que também prestam contribuição relevante para esta situação.

As agências reguladoras foram criadas para garantir atuação estatal imparcial e técnica no acompanhamento, fiscalização e regulação de contratos de longo prazo nos setores de infraestrutura, que envolvem investimentos relevantes do setor privado a serem amortizados em prazos longos, como 20 ou 30 anos. Assim, a estabilidade da regulação, a imparcialidade das decisões, a sua rapidez, solidez técnica e conformidade com as regras e com a lógica jurídica, econômica e financeira são essenciais para manter a credibilidade do sistema regulatório.

No entanto, é frequente que as agências reguladoras (i) atuem de forma errática, com comprometimento da segurança jurídica; (ii) negligenciem importantes regras procedimentais; ou (iii) divulguem inapropriadamente as informações relevantes sobre o setor regulado e sobre as suas próprias decisões.

\section{Descumpram contratos e frustrem a segurança jurídica}

Uma das razões para a criação das agências reguladoras consistia em dar mais estabilidade aos setores regulados. A ideia era a de que a concessão de poderes regulatórios a entidades técnicas, isoladas de influências políticas, favoreceria a previsibilidade, criando ambiente propício para o aporte de investimentos. Como desbaratar este projeto? Assegurando que a estabilidade e a segurança jurídica sejam comprometidas nos setores regulados pela atuação da própria agência.

A forma mais óbvia para fazê-lo é frustrar o cumprimento dos contratos, em especial em relação à garantia do equilíbrio econômicofinanceiro dos contratos e realização dos reajustes tarifários. Há aí o cenário propício para ações populistas e para violar os direitos e a expectativa dos concessionários. No caso de disposições relativas ao reequilíbrio econômico-financeiro, uma estratégia particularmente 
efetiva consiste na anulação de disposições contratuais firmadas anos antes, sob o argumento de mudança de orientação quanto à metodologia aplicável para o seu cálculo. Tome-se o caso emblemático da ação judicial intentada pela ARTESP e pelo Governo do Estado de São Paulo para anular aditivos celebrados em dezembro de 2006.38 A este respeito, argumente que é natural que práticas regulatórias evoluam e que novas formas de cálculo de reequilíbrio sejam desenvolvidas. E ignore que é exatamente por isso que se crê indispensável blindar o passado, preservando a validade e eficácia dos acordos assinados com base nas práticas vigentes à época da sua realização. ${ }^{39}$

Já no caso do reajuste tarifário, é cada vez mais raro o exemplo de Luiz Guilherme Schymura, então presidente do Conselho da ANATEL que, em 2003, lutou para impedir que o Governo ignorasse as regras de reajuste de tarifa dos contratos de concessão dos serviços de telefonia. Ao invés disso, tem sido frequente que os diretores de agências reguladoras convalidem reduções de tarifa ou ignorem o direito de reajustá-las quando o Chefe do Poder Executivo assim entender devido, ignorando que a manutenção do valor da tarifa e direito ao seu reajuste só podem ser alterados por acordo entre as partes. Diversas agências reguladoras, particularmente as estaduais, o fizeram após as manifestações sociais de 2013. 40

\footnotetext{
${ }^{38}$ Sobre o tema, vide reportagem da Folha de São Paulo de 18/05/2014, a qual relata a propositura de ação judicial em face de pelo menos oito concessionárias. Disponível em: $<$ http://www1.folha.uol.com.br/fsp/mercado/166483-governo-de-sp-abre-guerradas-rodovias.shtml $>$. Acesso em: 08 de agosto de 2017. Em alguns deles, a decisão de primeira instância foi favorável ao Estado, ocorrendo a anulação do aditivo, como na ação proposta contra a Concessionária rodoviária CCR AutoBAn. Disponível em: $<$ http://www.valor.com.br/empresas/4213400/justica-antecipa-fim-de-concessao-daanhanguera-e-bandeirantes $>$. Acesso em: 08 de agosto de 2017. Em outras, a justiça manteve o aditivo, como na proposta em face da Concessionária rodoviária TEBE. Disponível em: $<$ http://www.conjur.com.br/2016-jul-19/estado-nao-rever-contratoporque-ele-tornou-desvantajoso $>$. Acesso em: 08 de agosto de 2017.

${ }^{39}$ Esta crítica à ARTESP motivou uma resposta do diretor-geral da agência, Giovanni Pengue Filho, também publicada no site Jota. PENGUE FILHO, Giovanni. Quando valor de agência reguladora se mede por eficiência. Disponível em:

$<$ https://jota.info/artigos/quando-valor-de-agencia-reguladora-se-mede-por-eficiencia12052017>. Acesso em: 08 de agosto de 2017.

${ }^{40}$ A diminuição das tarifas de ônibus ocorreu em diversas cidades do país, como monstra reportagem jornalística do O Dia de 13/06/2013. Disponível em: $<$ http://odia.ig.com.br/noticia/brasil/2013-06-13/protestos-baixam-tafira-de-onibus-em-
} 
O grande mérito da estratégia de descumprimento contratos está em que os seus efeitos vão além do caso concreto. Cria-se a percepção geral de que quaisquer alterações nas condições políticas ou nas orientações das agências sobre questões regulatórias serão suficientes para fazê-las rever decisões passadas e reabrir os processos nos quais elas foram tomadas. Ou seja: consagra-se exatamente o cenário de insegurança que se quis evitar com a criação das agências reguladoras.

\section{Não liguem muito para procedimentos}

Uma segunda estratégia efetiva para minar a credibilidade das agências reguladoras consiste em negligenciar as regras procedimentais que regem (ou deveriam reger) a sua atuação. Ora, o procedimento é um mecanismo jurídico para garantir que as decisões de uma entidade pública sejam tomadas de forma legítima - e não de forma arbitrária. Afinal, decidir seguindo um procedimento é o inverso de decidir livremente. Justamente por isso, desconsiderar as regras procedimentais é forma eficaz de comprometer esta arquitetura institucional e pôr em cheque a sua própria legitimidade.

A estratégia pode ser utilizada tanto na produção normativa como nas chamadas "decisões individuais" (solução de uma controvérsia, imposição de uma sanção etc.). Tome-se a primeira hipótese, de produção normativa. Aqui, a forma mais recorrente de procedimentalização em todo o mundo é o uso da chamada Análise de Impacto Regulatório (AIR). Bem utilizada, a AIR tende a gerar uma regulação de maior qualidade (porque serve a levantar dados relevantes) e mais democrática (porque permite o debate de diferentes opções). ${ }^{41} \mathrm{Na}$ prática, no entanto, ela ainda

seis-capitais.html>. Acesso em: 08 de agosto de 2017. No entanto, em muitos casos a decisão foi revertida depois.

${ }^{41}$ Cf. a Recomendação do Conselho sobre Política Regulatória e Governança da OCDE (Organização para Cooperação e Desenvolvimento Econômico) pela adoção da Análise de Impacto Regulatório, de 22 de março de 2012. ORGANIZAÇÃO PARA COOPERAÇÃO E DESENVOLVIMENTO ECONÔMICO - OCDE. Recomendação do Conselho sobre Política Regulatória e Governança. 2012. Disponível em: http://www.oecd.org/gov/regulatorypolicy/Recommendation\%20PR\%20with\%20cover.pdf>. Acesso em: 08de agosto de 2017. No mesmo sentido, vide SALGADO, Lucia Helena; BORGES, Eduardo Bizzo de Pinho. Análise de Impacto Regulatório: uma abordagem exploratória. Texto para Discussão - IPEA, TD 1463, 2010. Disponível em: 
está muito longe de ser a regra no Brasil. ${ }^{42} \mathrm{Na}$ ausência de uma obrigação legislativa genérica, tem cabido às próprias agências reguladoras decidir quando e como valer-se deste mecanismo. Neste cenário, não é surpresa que, salvo poucas exceções no nível federal (como é o caso da ANVISA ${ }^{43}$ ), o uso da AIR ainda seja raro. Também no caso das chamadas decisões individuais, é comum a reclamação dos regulados sobre desrespeito de regras procedimentais e dos seus direitos de serem ouvidos, sendo esta a maior causa de contestações judiciais de decisões das agências.

Mas as agências podem ser ainda mais eficientes nesta estratégia de negligência a ritos procedimentais. Elas podem valer-se de disposições contratuais para ampliar os seus próprios poderes e as suas próprias margens de discricionariedade. Ao invés de procedimento, ampla liberdade. Num primeiro exemplo já testado, basta incluir em minutas de contrato fatores indeterminados que lhes dão amplos poderes de mudar a qualquer tempo os seus aspectos econômico-financeiros. Valham-se indiscriminadamente do famoso Fator X. Ignorem a lição de que, tecnicamente, a utilização deste mecanismo só faz sentido para contratos em setores cujos avanços tecnológicos criem periodicamente ganhos operacionais inesperados, como o setor de telecomunicações ou de distribuição de energia elétrica. ${ }^{44}$ Usem-no, portanto, mesmo em setores

$<\underline{\text { http://www.ipea.gov.br/portal/index.php?option=com content\&view }=\text { article\&id }=501}$ $\underline{0}$ >. Acesso em: 08 de agosto de 2017.

${ }^{42}$ Cf. MENDONÇA, José Vicente Santos de. Impacto Regulatório: um obscuro objeto de desejo. 2010. Disponível em: $<$ http://www.conjur.com.br/2010-set-14/analiseimpacto-regulatorio-ainda-obscuro-objeto-desejo $>$. Acesso em: 08 de agosto de 2017. E, em uma colocação mais recente, SALINAS, Natasha Schmitt Caccia. Por um uso abrangente da Análise de Impacto Regulatório no Brasil. 2016. Disponível em: $<$ http://www.direitodoestado.com.br/colunistas/natasha-salinas/por-um-usoabrangente-da-analise-de-impacto-regulatorio-no-brasil >. Acesso em: 08 de agosto de 2017.

${ }^{43}$ A ANVISA vem trabalhando na incorporação da Análise de Impacto Regulatório em suas práticas desde 2007, sendo pioneira e referência para a prática. Tanto é assim, que em 2008 a agência foi selecionada pelo como agência-piloto para o Programa de Fortalecimento da Capacidade Institucional para Gestão em Regulação (Pro-Reg) do Governo Federal, o qual buscou disseminar a prática da AIR no país. Disponível em: $<$ https://goo.g1/RbU2NY>; e <http://portal.anvisa.gov.br/analise-de-impactoregulatorio $>$. Acessos em: 08 de agosto de 2017.

44 “[n]esse caso (fator X) cuida-se de instrumento regulatório destinado a exigir que o concessionário gere e compartilhe com usuários ganhos de eficiência setoriais, não atribuíveis especificamente a diferenciais no seu desempenho. Não se trata de 
de infraestrutura pesada. Num segundo exemplo também não inédito, subordinem o direito ao reequilíbrio econômico-financeiro do contrato a fatores que as próprias agências estabelecerão a posteriori. ${ }^{45}$ Assim se cria incerteza sobre a indenização integral dos concessionários pela ocorrência de eventos cujo risco foi atribuído pelo contrato ou pela lei ao Poder Concedente. É o caso da utilização da metodologia do fluxo de caixa marginal para qualquer evento de desequilíbrio (e não apenas para a inclusão de novos investimentos no contrato), com taxa de desconto estipulada posteriormente pela agência reguladora, como tem acontecido nos contratos da ANTT e da ANAC.

\section{Negligenciem a importância da difusão informacional}

Uma última estratégia para comprometer a imagem e a reputação das agências consiste em negligenciar a importância da propagação de informações para a regulação. Há pelo menos duas formas distintas em que ela pode ser relevante.

Numa primeira forma, a difusão informacional é relevante como técnica ou estratégia regulatória. Neste sentido, a agência atua como um centro propagador das informações pertinentes ao setor regulado, tornando-as facilmente acessíveis a todos. Isto tende a ampliar a competitividade entre os players do mercado, além de possibilitar escolhas e comportamentos mais conscientes dos consumidores. A despeito disso, medidas tão básicas como a divulgação comparativa de diferentes planos de serviço oferecidos por diferentes operadoras de telefonia seguem sem ser implementadas pela ANATEL, para citar apenas um exemplo. A desculpa para esta inação tem sido a da constante mudança dos planos das operadoras - circunstância que não impediu o

atividade de reequilíbrio do contrato." RIBEIRO, Maurício Portugal. "PPP Mais" e o Regime dos Contratos de Concessão e PPP: erros, acertos e oportunidades que não deveriam ser perdidas. 2015, p. 38. Disponível em:

$<\underline{\text { https://pt.slideshare.net/portugalribeiro/ppp-mais-e-o-regime-dos-contratos-de- }}$ concesso-e-ppp>. Acesso em: 08 de agosto de 2017.

${ }^{45}$ Vide o ponto $\mathrm{n}^{\mathrm{o}} 08$ em RIBEIRO, Maurício Portugal. Novo pacote de infraestrutura do Governo Dilma: 15 erros que precisam ser corrigidos. 2015. Disponível em: $<$ https:/pt.slideshare.net/portugalribeiro/o-que-precisa-mudar-no-pil-final-publicadoem>. Acesso em: 08 de agosto de 2017. 
Banco Central, por exemplo, de disponibilizar comparativo semelhante relativo às tarifas bancárias. ${ }^{46}$

Numa segunda forma, a divulgação de informações é instrumento de legitimação das escolhas da própria agência. A importância desta específica forma de comunicação resulta particularmente evidente porque o trabalho de uma agência reguladora consiste em arbitrar interesses conflitantes (de diferentes tipos de usuários do serviço, da indústria regulada, do Poder Público etc.). ${ }^{47}$ No contexto de tomada de decisões tão complexas e tão propensas a gerar controvérsias, a boa comunicação é a chave para que uma medida seja compreendida e bem avaliada. Comunicar mal neste contexto é o caminho óbvio para que suas ações ou não possam ser avaliadas pela população, ou sejam necessariamente compreendidas como resultado de captura. Isso talvez explique porque inúmeras decisões racionais do ponto de vista econômico venham a ser largamente percebidas pela população como voltadas a favorecer a indústria regulada. Assim, por exemplo, a recente decisão da ANAC de liberar a cobrança de bagagens despachadas. Teria sido possível investir mais na divulgação de estudos e na explicação da regra tanto sob um ponto de vista da sua eficiência (no sistema anterior, passageiros que não despacham bagagens subsidiam aqueles que as levam), como do ponto de vista de sua naturalidade (trata-se de regra que vale em quase todo o mundo, com exceção apenas de México, Venezuela, China e Rússia), como, finalmente, do ponto de vista de suas prováveis consequências (redução de preços por maior amplitude concorrencial, a exemplo do que já vem acontecendo desde que se começou a adotar a

${ }^{46}$ As informações, incluindo relação das tarifas bancárias em ordem decrescente de valores entre as instituições financeiras, estão disponíveis no site do Banco Central.

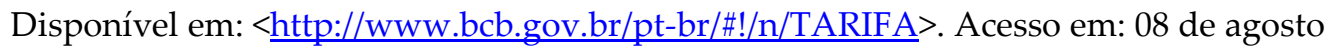
de 2017.

47 “(...) os novos órgão reguladores devem reunir uma grande capacidade de arbitramento dos interesses envolvidos com a atividade regulatória." e "pode-se dizer que as agências se prestam, basicamente, a: i) mediar interesses específicos existentes no setor regulado (...)", em MARQUES NETO, Floriano Azevedo. A Nova Regulação Estatal e as Agências Independentes. In: Carlos Ari Sundfeld. (Org.). Direito Administrativo Econômico. São Paulo, SP: Editora Malheiros/SBDP, 2000, p. 91-92. Cf. também MARQUES NETO, Floriano Azevedo. Agências Reguladoras Independentes: Fundamentos e seu Regime Jurídico. Belo Horizonte, MG: Editora Fórum, 2005. 
liberdade tarifária). Ao invés disso, ela foi objeto de tímidas manifestações oficiais ${ }^{48}$ atropeladas por indignações do senso comum.

\section{CONCLUSÃO}

Caso ainda não tenha ficado totalmente evidente, vale a pena esclarecer: o texto acima é irônico. Na realidade, o objetivo dos autores não é "oferecer dicas para a destruição das agências reguladoras". Ao invés disso, o que lhes move é a vontade de denunciar uma série de práticas que já vêm sendo adotadas por diferentes atores institucionais e que, aos seus olhos, possuem efeito deletério evidente sobre o projeto de Estado Regulador Brasileiro. Na oportunidade de celebração dos 20 anos deste projeto institucional, parece essencial fazer esta reflexão sobre o que deu errado até aqui, para que os problemas possam ser corrigidos nas próximas décadas.

\section{REFERÊNCIAS}

ARAGÃO, Alexandre dos Santos. As Funções e a Posição das Agências Reguladoras Independentes no Estado Contemporâneo. Dissertação (Mestrado em Direito), Universidade do Estado do Rio de Janeiro, Rio de Janeiro, 2001.

AZEVEDO, Eurico de Andrade. Agências Reguladoras. Revista de Direito Administrativo - RDA, No. 213, 1998.

CONFORTO, Glória. Descentralização e Regulação da Gestão de Serviços Públicos. Revista de Administração Pública - RAP, Vol. 32, 1, 1998.

${ }^{48}$ Cf. artigo do Diretor da ANAC, José Ricardo Pataro Botelho de Queiroz na Folha de São Paulo. QUEIROZ, José Ricardo Pataro Botelho de. Sem bagagem e com mais inclusão. 2016. Disponível em:

$<$ http://www1.folha.uol.com.br/opiniao/2016/12/1842673-sem-bagagem-e-com-maisinclusao.shtml>. Acesso em: 08 de agosto de 2017. 
COTIAS E SILVA, Arthur Adolfo. O Tribunal de Contas da União na História do Brasil: evolução histórica, política e administrativa (18901998). In: TRIBUNAL DE CONTAS DA UNIÃO. Prêmio Serzdello Corrêa 1998: Monografias Vencedoras. Brasília, DF: Tribunal de Contas da União/Instituto Serzdello Corrêa, 1999.

DI PIETRO, Maria Sylvia Zanella. Direito Administrativo. 30ª ed. Rio de Janeiro, RJ: Forense, 2017.

GUIMARÃES, Fernando Vernalha. O Direito Administrativo do Medo: a crise da ineficiência pelo controle. 2016. Disponível em:

$<$ http://www.direitodoestado.com.br/colunistas/fernando-vernalhaguimaraes/o-direito-administrativo-do-medo-a-crise-da-ineficienciapelo-controle>. Acesso em: 08 de agosto de 2017.

JORDÃO, Eduardo. A intervenção do TCU sobre editais de licitação não publicados: controlador ou administrador? Revista Brasileira de Direito Público - RBDP, Vol. 12, 47, 2014.

. Cobrança por bagagem: o que diz o Direito? Disponível em: $<$ https://jota.info/colunas/ supra/cobranca-por-bagagem-o-que-diz-odireito-24032017>. Acesso em: 08 de agosto de 2017.

. Controle Judicial de uma Administração Pública Complexa: a experiência estrangeira na Adaptação da Intensidade do Controle. São Paulo, SP: Malheiros/SBDP, 2016.

JORDÃO, Eduardo; LARDOSA, Arthur. Congresso x Agências: limites, só para os outros. Disponível em:

$<$ https://jota.info/colunas/supra/congresso-x-agencias-limites-para-osoutros-19122016>. Acesso em: 08 de agosto de 2017. 
JUSTEN FILHO, Marçal. O Direito das Agências Reguladoras Independentes. São Paulo, SP: Dialética, 2002.

. Curso de Direito Administrativo. 12ª ed. São Paulo, SP: Editora Revista dos Tribunais, 2016.

MARQUES NETO, Floriano Azevedo. A Nova Regulação Estatal e as Agências Independentes. In: Carlos Ari Sundfeld. (Org.). Direito Administrativo Econômico. São Paulo, SP: Editora Malheiros/SBDP, 2000 .

Agências Reguladoras Independentes: Fundamentos e seu Regime Jurídico. Belo Horizonte, MG: Editora Fórum, 2005.

MENDONÇA, José Vicente Santos de. Impacto Regulatório: um obscuro objeto de desejo. 2010. Disponível em:

$<$ http://www.conjur.com.br/2010-set-14/analise-impacto-regulatorioainda-obscuro-objeto-desejo $>$. Acesso em: 08 de agosto de 2017.

ORGANIZAÇÃO PARA COOPERAÇÃO E DESENVOLVIMENTO ECONÔMICO - OCDE. Recomendação do Conselho sobre Política Regulatória e Governança. 2012. Disponível em:

http://www.oecd.org/gov/regulatorypolicy/Recommendation\%20PR\%20with\%20cover.pdf $>$. Acesso em: 08de agosto de 2017.

PENGUE FILHO, Giovanni. Quando valor de agência reguladora se mede por eficiência. Disponível em: $<$ https://jota.info/artigos/quandovalor-de-agencia-reguladora-se-mede-por-eficiencia-12052017>. Acesso em: 08 de agosto de 2017.

RIBEIRO, Maurício Portugal. Comentários às Diretrizes Recentemente Publicadas do Novo Programa de Investimentos em Infraestrutura do Governo Federal. 2016. Disponível em: 
$<$ http://www.portugalribeiro.com.br/comentarios-as-diretrizesrecentemente-publicadas-do-novo-programa-de-investimentos-eminfraestrutura-do-governo-federal/>. Acesso em: 08 de agosto 2017.

. Novo pacote de infraestrutura do Governo Dilma: 15 erros que precisam ser corrigidos. 2015. Disponível em: $<\underline{\text { https://pt.slideshare.net/portugalribeiro/o-que-precisa-mudar-no-pil- }}$ final-publicado-em>. Acesso em: 08 de agosto de 2017.

. "PPP Mais" e o Regime dos Contratos de Concessão e PPP: erros, acertos e oportunidades que não deveriam ser perdidas. 2015, p. 38. Disponível em: $<\underline{\text { https://pt.slideshare.net/portugalribeiro/ppp-mais- }}$ e-o-regime-dos-contratos-de-concesso-e-ppp >. Acesso em: 08 de agosto de 2017.

SALAMA, Bruno Meyerhof; BARRIONUEVO, Arthur; PALMA, Juliana Bonacorsi de; DUTRA, Pedro. Processo de Nomeação de Dirigentes das Agências Reguladoras: uma Análise Descritiva. 2016, p. 04. Disponível em:

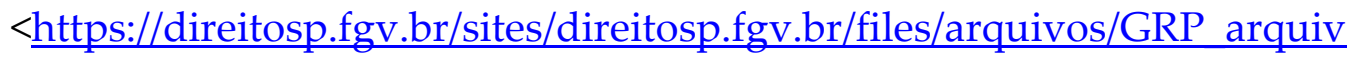
os/sumario executivo grp - pep 01.pdf $>$. Acesso em: 16 de maio de 2017.

SALGADO, Lucia Helena; BORGES, Eduardo Bizzo de Pinho. Análise de Impacto Regulatório: uma abordagem exploratória. Texto para Discussão - IPEA, TD 1463, 2010. Disponível em: $<$ http://www.ipea.gov.br/portal/index.php?option=com content\&view= article\&id=5010>. Acesso em: 08 de agosto de 2017.

SALINAS, Natasha Schmitt Caccia. Por um uso abrangente da Análise de Impacto Regulatório no Brasil. 2016. Disponível em: $<\underline{\text { http://www.direitodoestado.com.br/colunistas/natasha-salinas/por- }}$ um-uso-abrangente-da-analise-de-impacto-regulatorio-no-brasil >. Acesso em: 08 de agosto de 2017. 
SOUTO, Marcos Juruena Villela. Agências reguladoras. Revista de Direito Administrativo - RDA, No. 216, 1999.

SPECK, Bruno Wilhelm. Inovação e rotina no Tribunal de Contas da União: o papel da instituição superior de controle financeiro no sistema político-administrativo do Brasil. São Paulo, SP: Fundação Konrad-Adenauer-Stiftung, 2000.

QUEIROZ, José Ricardo Pataro Botelho de. Sem bagagem e com mais inclusão. 2016. Disponível em:

$<$ http://www1.folha.uol.com.br/opiniao/2016/12/1842673-sem-bagageme-com-mais-inclusao.shtml>. Acesso em: 08 de agosto de 2017.

SUNDFELD, Carlos Ari. Chega de Axé no Direito Administrativo. Disponível em: $<\underline{\text { http://www.sbdp.org.br/ }}$ artigos ver.php?idConteudo=100>. Acesso em: 08 de agosto de 2017. . Introdução às Agências Reguladoras. In: Carlos Ari Sundfeld (Org.). Direito Administrativo Econômico. São Paulo, SP: Editora Malheiros/SBDP, 2000.

Como Desestruturar Uma Agência Reguladora em Passos Simples How to Dismantle an Administrative Agency in Simple Steps Submetido em: 2017-07-31

Aceito em: 29-07-29 